\title{
Effects of Low-Power He-Ne Laser on the Growth of Yeast under High Pressure
}

\author{
Katsuhiro Tamura and Shinsuke Kishioka \\ Department of Chemical Science and Technology, Faculty of Engineering, The University of Tokushima, \\ Minamijosanjima-cho, Tokushima 770, Japan
}

\begin{abstract}
The effects of $\mathrm{He}-\mathrm{Ne}$ laser irradiation on the growth of yeast were investigated by counting viable cells at various temperatures $\left(15-43^{\circ} \mathrm{C}\right)$ and pressures $(0.1,50,100$, and $150 \mathrm{MPa})$. The laser irradiation was found to be able to retard the growth inhibitory effect of hydrostatic pressure thus stimulating the growth of yeast cells under pressures up to $100 \mathrm{MPa}$ [He-Ne laser, biostimulating effects, yeast, growth thermogram ]
\end{abstract}

\section{Introduction}

Laser radiation has been widely and variedly used in medicine and biology [1,2]. High-power laser radiation can destroy normal and neoplastic tissues. On the other hand, low-power $\mathrm{He}-\mathrm{Ne}$ laser (soft laser) is widely used in the field of medicine for the treatment of postsurgical headaches, post-therapeutic neuralgia (PTN), failure of skin ulcers to heal, rheumatic arthritis, and bronchial asthma. It is known that the irradiation of lowpower visible monochromatic red light such as He-Ne laser often stimulates metabolic systems in various cells and accelerates the growth. Irradiation of laser caused stimulation of DNA synthesis in cell and enhanced cell division rate.

On the contrary, high hydrostatic pressure acts as stresses to the organisms living under atmospheric pressure and gives various effects to their physiology and ecology. Generally the growth of common microorganisms (e.g., E. coli and yeasts) is retarded by pressurization up to $50 \mathrm{MPa}$ and it often leads microorganisms to death at higher pressures than $50 \mathrm{MPa}$. We have studied the behaviors of microorganisms under high pressure [3-6]. The retardation of the growth is one of the bottle necks for the studies and the application of microorganisms (e.g., alcoholic fermentation) under high pressure. The purpose of this paper is to check whether low-power $\mathrm{He}-\mathrm{Ne}$ laser irradiation can moderate or conquer the negative effects of high pressure on the growth of yeast.

\section{Materials and methods}

\subsection{Preparation of cultures}

The yeast Saccharomyces cerevisiae IFO 10149 was grown at $30^{\circ} \mathrm{C}$ in YPD medium containing $(\mathrm{g} / \mathrm{l})$ glucose, 20; polypeptone, 20; and yeast extract 10. Cultures in the logarithmic phase of growth were used. The logarithmic phase cells were suspended in fresh YPD medium and irradiated for 0 - $120 \mathrm{~min}$ under various pressures up to $150 \mathrm{MPa}$ at temperatures of 15 to $43^{\circ} \mathrm{C}$. A part of the suspensions was used to count viable cell numbers using YPD agar culture. The experiments were repeated at least three times and the average values were used as survival ratios.

\subsection{Measurements of metabolic heats of irradiated yeasts}

The metabolic heats of irradiated yeasts were measured using a microcalorimeter (Calorimetry Science Company, DSC
$4100)$ at $30^{\circ} \mathrm{C}$. The yeast suspensions were irradiated for desired time with a He-Ne laser $(8.5 \mathrm{~mW}$, wavelength $632.8 \mathrm{~nm}$, Senko Medical Instrument Mfg.) and then put in the ampoule of the calorimeter. It took about two days to get the growth-time curve (growth thermogram).

\subsection{High pressure apparatus}

A high pressure vessel $(130 \times 130 \times 130 \mathrm{~mm})$ with optical windows was used for the irradiation of laser under high pressures up to $150 \mathrm{MPa}$ (Fig.1). The light source of He-Ne laser was a Nippon Electric Co. product (GLG5260, $5 \mathrm{~mW}$ ). Optical power of laser was measured by ADVANTEST optical power multimeter (Q8221, Q82214 type). The temperature of the sample was kept constant by circulating water from thermostat.

\section{Results and discussion}

3.1. Confirmation of the biostimulating effects of laser by calorimetry

Much work has been made by many investigators to study quantitatively the biological activities of living cells and tissues by observing their metabolic heats [7]. The method is mainly based on the fact that the heat effect is strictly proportional to the

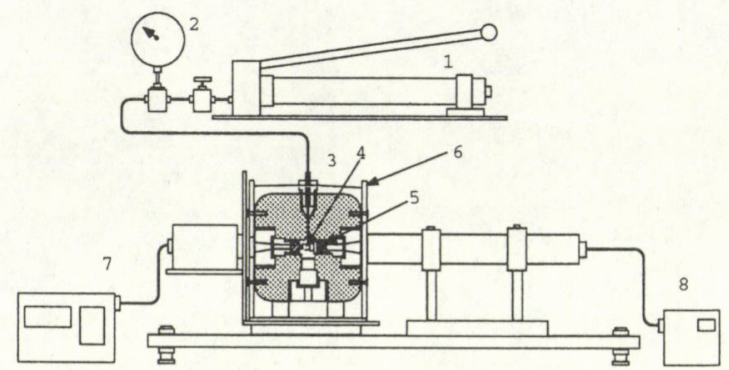

Fig. 1. High pressure system with $\mathrm{He}-\mathrm{Ne}$ laser.

1. High pressure pump. 2. Bourdon gauge. 3. High pressure vessel. 4. Inner sample cell. 5. Sapphire window. 6. Water bath. 7. Optical power meter. 8. He-Ne laser system. 

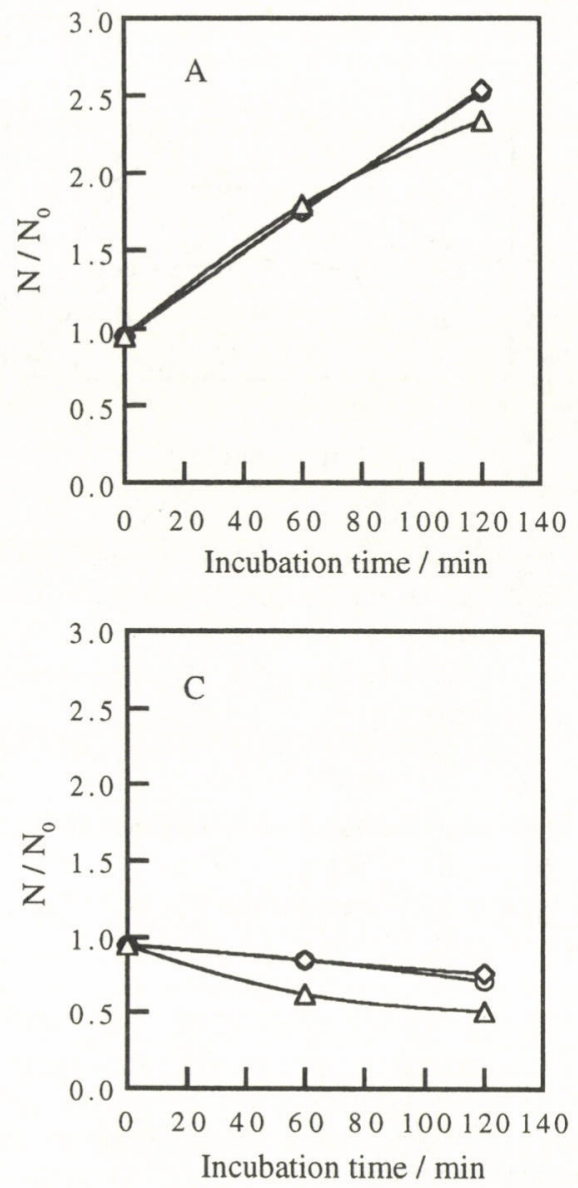

metabolic activity and in most cases a magnitude of calorimetric signal which is given by power unit ( $\mu$ watt) is simply employed as an index to express the biological activities.

In order to check the dependence of irradiation time, the ratio of the metabolic heats of irradiated and nonirradiated yeasts was plotted against irradiation time. There was a clear stimulation effect of laser for the yeast irradiated for up to $30 \mathrm{~min}$. However, the irradiation for more than $60 \mathrm{~min}$ did not accelerate the growth of yeast any more.

\subsection{Laser stimulation effects under high pressure}

The maximum biomass in yeasts is accumulated at a wavelength of $632.8 \mathrm{~nm}$ of He-Ne laser. Figure 2 shows the effects of pressure and irradiation of $\mathrm{He}-\mathrm{Ne}$ laser on the growth of yeast cells at $30^{\circ} \mathrm{C}$. At atmospheric pressure (Fig.2(A)), yeast cells irradiated with $\mathrm{He}-\mathrm{Ne}$ laser showed similar pattern to that of nonirradiated yeast, although a small effect of the irradiation was found for $120 \mathrm{~min}$ irradiation. At $50 \mathrm{MPa}$ (Fig.2(B)), the growth of nonirradiated yeasts was inhibited, however, the viable cell num-

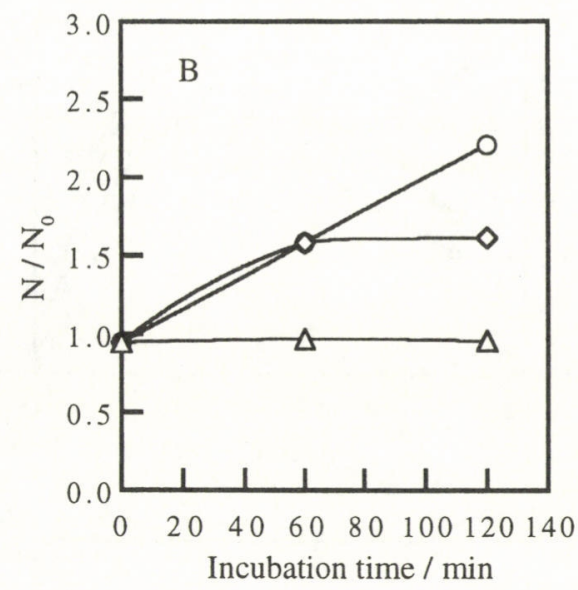

Fig. 2. Effects of low-power He-Ne laser irradiation under high pressure on the growth of yeast cells at $30^{\circ} \mathrm{C}$.

Numbers of viable cells were determined by counting colonies on nutrient medium.

$\mathrm{N}$, colonies after incubation; $\mathrm{N}_{0}$, colonies before incubation.

Applied pressure: A, $0.1 \mathrm{MPa} ; \mathrm{B}, 50 \mathrm{MPa} ; \mathrm{C}, 100 \mathrm{MPa}$. Irradiation time: $\triangle, 0$ min (nonirradiated); $\diamond, 0-60 \mathrm{~min} ; \bigcirc, 0-120 \mathrm{~min}$ (full time). bers of irradiated ones were increased. The rate of increase in the viable cell numbers corresponded to that of the nonirradiated ones at $0.1 \mathrm{MPa}$. In spite of the laser irradiation, the viable cell numbers decreased at $100 \mathrm{MPa}$, although they were higher than those of the nonirradiated yeasts (Fig.2(C)). The effect of laser irradiation completely disappeared at pressures higher than $150 \mathrm{MPa}$.

Figure 3 shows the effects of the laser irradiation on the growth at various temperatures $\left(15-43^{\circ} \mathrm{C}\right)$ and pressures $(0.1,50$, and $100 \mathrm{MPa}$ ). All pressurization time is $120 \mathrm{~min}$. At about $30^{\circ} \mathrm{C}$ which is the optimum temperature concerning the growth of yeast at atmospheric pressure, the viability became maxima under almost all conditions. At $0.1 \mathrm{MPa}$ (Fig.3(A)), viable cell numbers of irradiated yeasts are larger than those of nonirradiated ones, although the results of the irradiation time of 60 and $120 \mathrm{~min}$ are almost same. The effects of laser irradiation were largest at 50 $\mathrm{MPa}$ (Fig.3(B)); especially at $25-30^{\circ} \mathrm{C}$ the ratio of the viable cell numbers after and before incubation became more than two times that of nonirradiated one. Since $50 \mathrm{MPa}$ is a limit of the growth of yeast, nonirradiated cells do not grow. However, the cells 

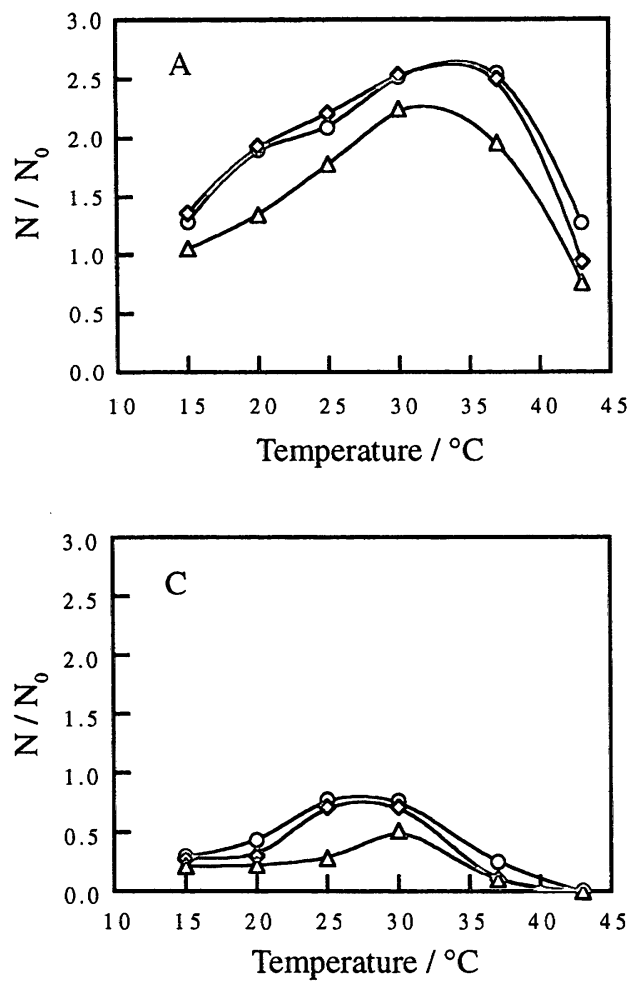

irradiated for $120 \mathrm{~min}$ were stimulated about 2.3 times of $\mathrm{N}_{0}$, the value of $\left(\mathrm{N} / \mathrm{N}_{0}\right)$ correspond to that of the nonirradiated one at 0.1 $\mathrm{MPa}$. This means that laser irradiation completely compensates the retardation of the growth of yeast due to pressurization of 50 $\mathrm{MPa}$. Even at $100 \mathrm{MPa}$ (Fig.3(C)), the viable cell numbers of irradiated yeast increased at $25-30^{\circ} \mathrm{C}$.

As mentioned above, it was found that $\mathrm{He}-\mathrm{Ne}$ laser irradiation could moderate or compensate the effects of high pressure, high temperature, and low temperature which often hinder the growth of yeast cells. Karu reported that when some yeasts were irradiated by He-Ne laser, the protein syntheses in the cells were most accelerated at the dose of $4 \times 10-3 \times 10^{3} \mathrm{~J} / \mathrm{m}^{2}$ [1]. Although we used $10-100$ times higher dose than Karu et al. used, the biostimulating effects of laser on yeast cells were confirmed under pressures up to $100 \mathrm{MPa}$.

The mechanisms of biostimulating effects of laser are not yet clear. One of the explanations is that respiratory chain components are important as primary photoacceptors and the absorbed light quanta induces the changes in the redox state of the respiratory chain [8]. Other possibilities are the effects of laser on the chromophores which compose pigments in cells and accept photons, and the effects on the proteins which support the chromophores.

Low-power He-Ne laser does not always stimulate the metabolism of organisms. Long time irradiation (high dose) often damages photoacceptors and causes the inhibition of metabolism

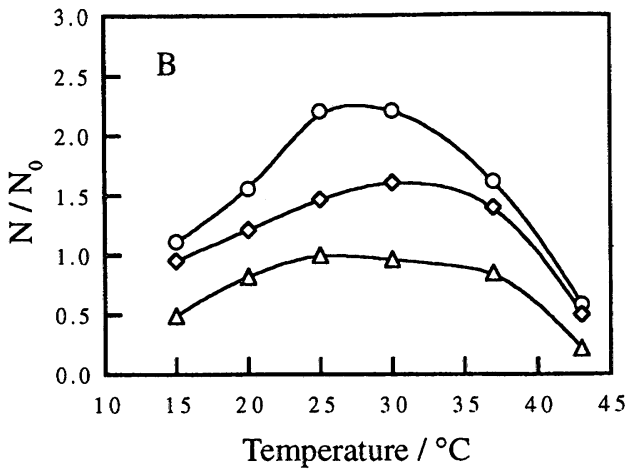

Fig. 3. Effects of low-power He-Ne laser irradiation on the growth of yeast cells at various temperetures and pressures.

$\mathrm{N}$, colonies after incubation; $\mathrm{N}_{0}$, colonies before incubation.

Applied pressure: A, $0.1 \mathrm{MPa} ; \mathrm{B}, 50 \mathrm{MPa}$;, 100 $\mathrm{MPa}$.

Irradiation time: $\Delta, 0 \mathrm{~min}$ (nonirradiated); $\diamond, 0-$ $60 \mathrm{~min}$; $\bigcirc, 0$ - $120 \mathrm{~min}$ (full time).

Pressure and temperature were applied for $120 \mathrm{~min}$.

and even the death of the cells. There are many negative reports which doubt the biostimulating effects of low-power laser in clinical levels. The growth rates of human cells are very slow compared to that of bacterial and yeast cells and the control of growth of tissues or organs is very complex processes compared to that of each cell. So we have to discuss the various phenomena induced by the laser radiation in more detail.

\section{References}

[1] T. I. Karu, Photobiology of Low-power Laser Therapy, Harwood Academic Publishers, 1989.

[2] T. I. Karu, IEEE J. Quantum Electronics, QE-23, 1703 (1987).

[3] K. Tamura, T. Shimizu, and H. Kourai, FEMS Microbiol. Lett., 99, 321 (1992).

[4] K. Tamura, Y. Muramoto, and H. Kourai, Biotech. Lett., 15, 1189 (1993).

[5] K. Tamura, S. Kishioka, M. Miyashita, and K. Iijima, Biotech. Techniques, 10, 339 (1996).

[6] K. Tamura et al., High Pressure Bioscience and Biotechnology, Progress in Biotechnology Vol.13, R. Hayashi and C. Balny Eds, Elsevier, 1996, pp.101, 113, 185, 261, 387.

[7] A. E. Beezer, Biological Microcalorimetry, Academic Press, New York, 1980.

[8] O. Tiphlova and T. I. Karu, Photochem. Photobiol., 48, 467 (1988). 